ORIGINAL ARTICLE

\title{
Early growth and childhood obesity: a historical cohort study
}

S Kinra, J H Baumer, G Davey Smith

See end of article for authors' affiliations

.....................

Correspondence to: Sanjay Kinra, Canynge Hall, Whiteladies Road, Bristol BS8 2PR, UK; Sanjay.Kinra@bristol.ac. uk

Accepted 25 July 2005 Published Online First 30 August 2005

Objective: To investigate to what extent prenatal, early postnatal, and late postnatal growth predicts risk of childhood obesity.

Methods: This was a historical cohort study of 1335 full term singletons born in southwest England in 1989. The main outcome measure was body mass index (BMI) at age 7. Absolute weights at birth, 6 weeks, and 18 months, and change in weights during the intervening periods were measured. Measures were examined as $z$ scores standardised to the 1990 UK reference population.

Results: $\mathrm{BMI}$ at age 7 was positively associated with $\mathrm{z}$ scores for weight at all ages. Regression coefficients (95\% confidence intervals) were: $0.16(0.11$ to 0.22$), 0.19(0.15$ to 0.24$)$, and $0.29(0.26$ to 0.33$)$ for weights at birth, 6 weeks, and 18 months, respectively. Regression coefficients for birth weight, early weight gain (change in weight $z$ score between birth and 6 weeks), and late weight gain (change in weight $z$ score between 6 weeks and 18 months), adjusted for each other were: 0.32 (0.27 to 0.38$), 0.31(0.26$ to 0.37$)$, and $0.28(0.23$ to 0.32$)$, respectively. There was no statistical evidence for interaction among weights, weight gains, or social deprivation. Social deprivation independently predicted BMI at age 7, the major influence being weight gain after 6 weeks of life.

Conclusions: These data suggest that obesity risk is acquired gradually over the perinatal and postnatal periods, instead of during a prenatal or early postnatal critical window. The association of obesity risk with social circumstances and the timing of its origin offer pointers to some underlying determinants of obesity.

lisina ntrauterine life has been identified as a critical time period for the development of obesity. ${ }^{2}$ Both over-nutrition and under-nutrition during this period have been implicated. ${ }^{3-5}$ Some have suggested the importance of growth in the first 2 years of life, while more recently the focus has narrowed down to growth acceleration in the first few weeks after birth. $^{5-9}$ Better understanding of the relative importance of growth in the prenatal, early, and late postnatal periods in determining future obesity risk may allow us to focus interventions to time periods when they could be expected to have most beneficial effect. We have therefore investigated the extent to which growth in the prenatal, early postnatal (birth to 6 weeks), and late postnatal (6 weeks to 18 months) periods predicts future risk of childhood obesity in a historical cohort of children from southwest England.

\section{METHODS}

\section{Study cohort}

Since 1988, data relating to all hospital births in Plymouth (Devon, UK) have been routinely stored on the Child Health Computer. The data collected include date of birth, sex of the child, birth weight (in grams), gestation (in completed weeks), whether the child was a multiple birth, parity of the mother, whether breast feeding was initiated after birth, and residential postcode of the parents. Health visitors carry out health checks on all children at the ages of 6 weeks and 18 months. The examinations include measurement of weight using an electronic scales and these data, along with the date of examination, are added to the computerised records of the children.

During 1994-96, all school children in the city of Plymouth between the ages of 5 and 14 years were measured during a growth surveillance study. The details of this study and the methodology used have been described in detail elsewhere. ${ }^{10}$ Trained school nurses carried out the measurements using a standardised protocol. All measurements were carried out with children in their vests and pants. Height was measured to the nearest completed millimetre using a portable self calibrating minimeter (Raven Equipment Limited, Essex, UK). The accuracy of the instrument was checked with a calibrated rule both before and after each measuring session. An average of three readings was taken with the head position in Frankfurt plane. Weight was measured once with an electronic scales (Seca, Birmingham, UK) to the nearest $100 \mathrm{~g}$.

Data on children from this growth surveillance study were linked to the routinely collected data from birth and health visitor examinations for a single year, that is 1989. This was the earliest year for which there were good quality computerised data. Linkage was based on the child's own name and date of birth, and parental names and address. We anticipated that the majority of children born in Plymouth in 1989 and still resident in the city during 1994-96 would be successfully linked in this way, as over $95 \%$ of the childhood population attends school locally.

\section{Study definitions}

We considered only term (37-42 weeks gestation), singleton births for the purposes of this study.

\section{Main outcome and exposure}

The main outcome measure was body mass index standard deviation (SD) (BMI z score) at age 7 years. Weights at birth, 6 weeks, and 18 months were also standardised to the British reference population and expressed as $\mathrm{z}$ scores. ${ }^{11}$ This allowed comparisons that were independent of the age and sex of the child. Birth weight z scores were corrected for gestational age, and used as a proxy for prenatal weight gain. Early (birth to 6 weeks) and late postnatal (6 weeks to 18 months) growths were represented by weight gain during these periods, and calculated as the difference in z scores for weights between the end and the beginning of each period. 
Table 1 Distribution of variables among children included and excluded from the analyses. Values are means (SD) unless stated otherwise

\begin{tabular}{lclccc}
\hline & Included, mean (SD) & $\mathbf{n}$ & Excluded, mean (SD) & $\mathbf{n}$ & p value \\
\hline Age at final exam (years) & $6.94(0.25)$ & 1335 & $6.94(0.25)$ & 580 & 0.89 \\
Male sex (\%) & $49.2 \%$ & 1335 & $50.8 \%$ & 1917 & 0.39 \\
First born (\%) & $42.6 \%$ & 1335 & $41.7 \%$ & 1917 & 0.62 \\
Ever breast fed (\%) & $54.3 \%$ & 1230 & $46.8 \%$ & 1321 & $<0.001$ \\
Socially deprived* (\%) & $22.5 \%$ & 1306 & $26.0 \%$ & 1808 & 0.026 \\
Body size indices & & & & 1916 & 0.48 \\
Birth weight (kg) & $3.40(0.46)$ & 1335 & $3.41(0.45)$ & 1916 & 0.54 \\
Birth weight (z score) & $-0.04(0.95)$ & 1335 & $-0.02(0.92)$ & 1251 & 0.58 \\
6 week weight (z score) & $0.18(1.17)$ & 1335 & $0.16(1.16)$ & 1157 & 0.86 \\
18 month weight (z score) & $0.35(1.35)$ & 1335 & $0.39(1.42)$ & 574 & 0.90 \\
Weight at age 7 (z score) & $0.27(1.55)$ & 1335 & $0.26(1.48)$ & 575 & 0.82 \\
Height at age 7 (z score) & $0.05(1.01)$ & 1335 & $0.06(1.00)$ & 574 & 0.90 \\
BMl at age 7 (z score) & $0.02(0.99)$ & 1335 & $0.02(0.97)$ & & \\
\hline *Defined as the most deprived quarter of population according to Townsend scores. & & & \\
\hline
\end{tabular}

\section{Covariates}

The covariates considered in the analysis were sex and birth order of the child (first born or otherwise), breast feeding status (ever breast fed or never breast fed), and social deprivation of the household when the child was 7 years old. Social deprivation was assessed by using the Townsend score that incorporates four census (1991) variables: general lack of material security (unemployment); material living conditions (overcrowding); wealth (owner occupation is used as a proxy indicator); and income (car ownership is used as a proxy indicator). ${ }^{12}$ We used enumeration district level data (approximately 150 households) standardised to the Devon county population. The variable was dichotomised into poor (the poorest quarter of the population according to Townsend score) or otherwise for analyses.

\section{Statistical analysis}

Multiple linear regression modelling was used for analyses. Growth implies a change in body size over time, and can be modelled as the difference in body size between time points of interest. ${ }^{56}$ Alternatively, the relevant body sizes can be incorporated into regression models directly, assuming that the effect of later size (controlled for early size) provides an estimate of the effect of growth on later outcome. ${ }^{13}$ We have analysed the data in both ways. For the first approach, we modelled birth weight, early weight gain, and late weight gain; for the second, we modelled weights at birth, 6 weeks, and 18 months. Univariable models were followed by bivariable models that included pairs of weights or weight gains, as appropriate. Multivariable models included all three weights (or alternatively birth weight with the two weight gains), with and without other covariates (that is, male sex, first born, ever breast fed, and poorest fourth of social deprivation).

We tested for interaction among the weights/weight gains and also for their interaction with social deprivation. The interactions were examined in continuous and categorical forms of these variables. As continuous variables, we tested for linear (product of the two variables) and quadratic (product of the squares of the variables) associations. For categorical forms of these variables, birth weight was categorised into lower half of birth weight (negative $\mathrm{z}$ score for birth weight) or otherwise, and weight gain was categorised into accelerated (greater than 0.67 SD increase), decelerated (greater than $0.67 \mathrm{SD}$ decrease) and no change (increase or decrease of less than $0.67 \mathrm{SD}$ ) categories, since 0.67 SD represents the width of each centile band on a standard growth chart. ${ }^{5}$

\section{RESULTS}

There were 3252 term singleton births in Plymouth in 1989 for 3251 of which birth weights were available. Of these 59\% were successfully linked to the data from the growth surveillance study at age 7 . Only those children for whom weights were available for all four data points, that is, birth, 6 weeks, 18 months, and 7 years, were considered for analysis $(\mathrm{n}=1335 ; 41 \%)$. Apart from being marginally less deprived and having slightly higher breast feeding rates, those included were similar to those excluded from the analyses (table 1). The mean age of the cohort at the time of final examination was 6.9 years (range: 6.2-7.5 years), and approximately half were girls. The mean birth weight was $3.4 \mathrm{~kg}$ and the mean BMI at age 7 was $15.9 \mathrm{~kg} / \mathrm{m}^{2}$, similar to the UK reference values (table 1). Although the standard deviations of height and BMI z scores at age 7 were near 1 , those for weight were near 1.5. The means (SD) of early and late weight gains were 0.22 (1.03) and 0.18 (1.30), respectively.

The correlation coefficients for weights and weight gains used in the analyses are presented in table 2. BMI at age 7 was positively associated with $\mathrm{z}$ scores for weight at all ages (table 3 ). In bivariable and multivariable models incorporating absolute weights ( $\mathrm{z}$ scores) only, the later weights explained most of the variation in BMI (table 3 ). In the models including weight gains (z scores), all three measures (that is, birth weight, early weight gain, and later weight) contributed roughly equally to the variation in BMI (table 4). In both weight and weight gain models, addition of other covariates (that is, male sex, first born, ever breast fed, and social deprivation) did not alter the results materially (data not presented). Social deprivation (poorest fourth) was an independent predictor of BMI, with regression coefficients (95\% confidence intervals) of: $0.13(0.003$ to 0.26$)$ for the unadjusted model $\left(\mathrm{R}^{2}=0.002\right)$, and $0.17(0.05$ to 0.29$)$ for the model adjusted for birth weight, and early and late weight gains $\left(\mathrm{R}^{2}=0.17\right.$ for the model).

There was no strong statistical evidence for interaction between weights or weight gains when examined as continuous or categorical variables ( $p$ values for all interaction tests were greater than 0.1). Similarly, there was no strong statistical evidence for interaction between any of the weights/weight gains and social deprivation ( $p$ values for interaction tests greater than 0.1). However, children from the most deprived fourth of the population had higher BMI at age 7 despite being lighter at birth (table 5). Deprived children put on most of the weight after 6 weeks of life; they were also less likely to be breast fed ( $31 \%$ v 54\%; $<<0.001)$, although breast feeding status itself was not an independent 
Table 2 Correlation coefficients for weights, weight gains, and BMI z scores at age 7

\begin{tabular}{|c|c|c|c|c|c|c|c|}
\hline & $\begin{array}{l}\text { Birth weight } \\
\text { (z score) }\end{array}$ & $\begin{array}{l}6 \text { week } \\
\text { weight } \\
\text { (z score) }\end{array}$ & $\begin{array}{l}18 \text { month } \\
\text { weight } \\
\text { (z score) }\end{array}$ & $\begin{array}{l}\text { BMI at age } 7 \\
\text { (z score) }\end{array}$ & $\begin{array}{l}\text { Birth to } \\
6 \text { weeks } \\
\text { weight change } \\
\text { (z score) }\end{array}$ & $\begin{array}{l}6 \text { weeks to } \\
18 \text { months } \\
\text { weight change } \\
\text { (z score) }\end{array}$ & $\begin{array}{l}\text { Birth to } \\
18 \text { months } \\
\text { weight change } \\
\text { (z score) }\end{array}$ \\
\hline Birth weight (z score) & 1.00 & & & & & & \\
\hline 6 week weight ( $\mathrm{z}$ score) & 0.54 & 1.00 & & & & & \\
\hline 18 month weight ( $z$ score) & 0.32 & 0.47 & 1.00 & & & & \\
\hline BMI at age 7 (z score) & 0.15 & 0.23 & 0.40 & 1.00 & & & \\
\hline $\begin{array}{l}\text { Birth to } 6 \text { weeks weight } \\
\text { change (z score) }\end{array}$ & -0.31 & 0.63 & 0.24 & 0.12 & 1.00 & & \\
\hline $\begin{array}{l}6 \text { weeks to } 18 \text { months weight } \\
\text { change ( } \mathrm{z} \text { score) }\end{array}$ & -0.15 & -0.41 & 0.61 & 0.21 & -0.32 & 1.00 & \\
\hline $\begin{array}{l}\text { Birth to } 18 \text { months weight } \\
\text { change ( } z \text { score) }\end{array}$ & -0.37 & 0.09 & 0.76 & 0.29 & 0.45 & 0.70 & 1.00 \\
\hline
\end{tabular}

predictor of BMI in this cohort. There was a strong negative association between weights/weight gains as expected (all p values less than 0.001 ), suggesting that small children tend to grow faster and vice versa.

\section{DISCUSSION}

BMI at age 7 showed positive and progressively stronger associations with $\mathrm{z}$ scores for weight at all ages. In models incorporating absolute body weights, the later weights explained most of the variation in BMI. In models including weight gains, all three measures (that is, birth weight, early weight gain, and later weight) contributed equally to the variation in BMI. These data suggest that obesity risk is gradually accrued over the perinatal and postnatal periods, instead of there being a narrow critical window in the prenatal or early postnatal period, as has been suggested previously. The association of obesity risk with social circumstances and the timing of its origin offer pointers to some of the underlying determinants of obesity.

\section{Study limitations}

The main limitation of this study is that it is based on a historical cohort established by linkage, and includes less than half $(41 \%)$ of the term singletons born locally. This may have introduced bias into our results. Comparison of available data, however, showed that those included were largely similar to those excluded from the analyses. Although the standard deviations of $\mathrm{z}$ scores for earlier body weights (birth and 6 weeks) were reasonably close to 1 (suggesting that the population is similar to the UK population), they appeared to widen with age, suggesting a greater variability in the weights (though not in the BMI) of this population. Plymouth is relatively deprived but also has considerable socio-economic variations within it. ${ }^{14}$ We have previously shown a strong social gradient in child obesity in a large cross section of children from Plymouth, of which the present cohort is a subgroup. ${ }^{10}$ The greater variability of weights at later ages may be a reflection of underlying social variability.

Another potential shortcoming of this study could be that the measurements at 6 weeks and 18 months were carried out during routine health visitor examinations and were not standardised. Bias introduced as a result would be nondifferential and would only have weakened the observed association between later weight and BMI. Others who have used such routine health visitor examination data have found it to be reasonably robust. ${ }^{15}$ We did not have data on parental fatness, which has been shown to be associated with both birth weight and obesity among offspring and could potentially influence any observed association between early growth indices and later BMI. ${ }^{16}$

\section{Conflict of findings between studies}

Previous studies have variously identified prenatal, early postnatal, and postnatal periods as the time when child obesity risk is most established. ${ }^{1256917-22}$ The relationship between rapid growth in infancy and childhood, and obesity in later life has also been the subject of a recent systematic review. ${ }^{23}$ These studies and overview suggest a consistent pattern of positive associations between birth weight and/or weight gain in early childhood (variously defined) on one hand and measures of body fatness in later life on the other. However, our interpretation of the data is at variance with that of the earlier studies. A potential explanation lies in the way the data were analysed. Studies have focussed on individual time periods of interest, in isolation, rather than trying to compare their importance relative to other time periods. If obesity risk is indeed accrued gradually over the course of early life (prenatal, infancy, and childhood), then a

Table 3 Linear regression coefficients for body weights and BMI z scores at age 7

\begin{tabular}{|c|c|c|c|c|}
\hline Models* & $\begin{array}{l}\text { Birth weight (z score) } \\
\text { regression coefficient } \\
(95 \% \mathrm{Cl})\end{array}$ & $\begin{array}{l}6 \text { week weight ( } z \text { score) } \\
\text { regression coefficient } \\
(95 \% \mathrm{CI})\end{array}$ & $\begin{array}{l}18 \text { month weight (z score) } \\
\text { regression coefficient } \\
(95 \% \mathrm{Cl})\end{array}$ & $\mathbf{R}^{2}$ \\
\hline \multirow[t]{3}{*}{ Univariable models } & $0.16(0.11$ to 0.22$)$ & - & - & 0.02 \\
\hline & - & $0.19(0.15$ to 0.24$)$ & - & 0.05 \\
\hline & - & - & $0.29(0.26$ to 0.33$)$ & 0.16 \\
\hline \multicolumn{5}{|l|}{ Bivariable models } \\
\hline Model 1 & $0.05(-0.02$ to 0.11$)$ & $0.17(0.12$ to 0.22$)$ & - & 0.05 \\
\hline Model 2 & - & $0.04(-0.01$ to 0.09$)$ & $0.28(0.24$ to 0.32$)$ & 0.16 \\
\hline Model 3 & $0.03(-0.02$ to 0.08$)$ & - & $0.29(0.25$ to 0.32$)$ & 0.16 \\
\hline Multivariable model & $0.01(-0.05$ to 0.07$)$ & $0.03(-0.02$ to 0.09$)$ & $0.28(0.23$ to 0.32$)$ & 0.16 \\
\hline
\end{tabular}

*Models: univariable models include only one of the three variables, that is, birth weight, 6 week, or 18 month weight $z$ scores; bivariable models: model 1 includes birth weight and 6 week weight $z$ scores, model 2 includes 6 week weight and 18 month weight $z$ scores, and model 3 includes birth weight and 18 month weight $z$ scores; multivariable model includes all three variables in the model, that is, birth weight, 6 week, and 18 month weight $z$ scores. 
Table 4 Linear regression coefficients for weight gains and BMI $z$ score at age 7

\begin{tabular}{|c|c|c|c|c|}
\hline Models* & $\begin{array}{l}\text { Birth weight (z score) } \\
\text { regression coefficient } \\
(95 \% \mathrm{Cl})\end{array}$ & $\begin{array}{l}\text { Early weight gain } \\
\text { (z score) regression } \\
\text { coefficient }(95 \% \mathrm{CI})\end{array}$ & $\begin{array}{l}\text { Late weight gain } \\
\text { (z score) regression } \\
\text { coefficient }(95 \% \mathrm{CI})\end{array}$ & $\mathbf{R}^{2}$ \\
\hline \multirow[t]{3}{*}{ Univariable models } & $0.16(0.11$ to 0.22$)$ & - & - & 0.02 \\
\hline & - & $0.11(0.06$ to 0.16$)$ & - & 0.01 \\
\hline & - & - & $0.16(0.12$ to 0.20$)$ & 0.04 \\
\hline \multicolumn{5}{|l|}{ Bivariable models } \\
\hline Model 1 & $0.22(0.16$ to 0.28$)$ & $0.17(0.12$ to 0.22$)$ & - & 0.05 \\
\hline Model 2 & - & $0.20(0.14$ to 0.25$)$ & 0.21 (0.17 to 0.25$)$ & 0.08 \\
\hline Model 3 & $0.20(0.14$ to 0.25$)$ & - & $0.18(0.14$ to 0.22$)$ & 0.08 \\
\hline Multivariable model & $0.32(0.27$ to 0.38$)$ & 0.31 (0.26 to 0.37$)$ & $0.28(0.23$ to 0.32$)$ & 0.16 \\
\hline
\end{tabular}

*Models: univariable models include only one of the three variables, that is, birth weight, early or late weight gain z scores; bivariable models: model 1 includes birth weight and early weight gain z scores, model 2 includes early and late weight gain z scores, and model 3 includes birth weight and late weight gain z scores; multivariable model includes all three variables in the model, that is, birth weight, and early and late weight gain $\mathrm{z}$ scores. Early weight gain: change in $\mathrm{z}$ score for weight between birth and 6 weeks; late weight gain: change in z score for weight between 6 weeks and 18 months.

focus on any one narrow window period (without simultaneously controlling for the effect of other periods) will result in that period appearing important.

Within the prenatal period, both under- and over-nutrition are implicated..$^{3-5}$ Only one study concluded that fetal undernutrition rather than over-nutrition was important, despite showing that rapid weight gain in the first 2 years of life was associated with higher BMI at age $5 .^{5}$ The interpretation of rapid weight gain as a proxy for fetal under-nutrition was based on the inverse association noted between birth weight and weight gain in infancy. However, rapid weight gain in infancy, unadjusted for birth weight, may not be an appropriate proxy for fetal under-nutrition, as smaller babies would be expected to demonstrate faster growth than larger babies even under equivalent environmental circumstances. ${ }^{13}$ This is because of a statistical phenomenon, which causes the second of the two related measurements to be closer to the mean than the first (regression to the mean). ${ }^{24} \mathrm{~A}$ strong inverse association between pairs of adjacent weights or weight gains was seen in our study and has been noted in other studies. ${ }^{925}$ We also used BMI, which is influenced by both lean and fat mass, as the main measure of obesity. There is evidence to suggest that fetal under-nutrition may alter the relative distribution of these two components (rather than overall mass) or selectively program central adiposity; these outcomes were not available to us. ${ }^{24} 26$

\section{Analytical and interpretation issues in studies of growth and later health}

For regression modelling of the effects of growth on later health outcomes, two approaches are commonly employed in multivariable analyses: those that use change in weight between two time points as a measure of growth and others that incorporate weights at various time points in the models directly. ${ }^{5613}$ The models underlying these approaches are equivalent and should result in similar conclusions. However, the use of both approaches in the same dataset may sometimes provide additional insights, as was the case in this study. The first approach suggested that growth in the three time periods of interest predicted later BMI roughly equally. The second approach, in addition, underlined the fact that these body weights lie along the same causal pathway, which limits the usefulness of standard regression techniques in modelling growth. While the standard regression techniques may suffice in situations where measurements of body weight are reasonably apart in time (such as birth weight and adult weight), they are far less informative in modelling early growth where several weights are considered a short time apart. ${ }^{13}$ Due to the temporal proximity of the measurements (hence high correlation) and their relationship along the causal pathway, the later measurements may dominate the association, thereby potentially underestimating the role of earlier growth periods.

The interpretation of the associations between growths at different stages of life with later health outcomes is complicated. Human growth is plastic and the rate of growth at any time point reflects not only the current environment but also the past environment of the individual (concept of catch up growth following a period of slow growth) and perhaps the environment of preceding generations, not to mention genes. ${ }^{27}{ }^{28}$ The available statistical techniques define growth as rapid or slow according to the deviation from the norm. Comparison with peers as a means of defining abnormality is therefore inherently limiting when it is used

Table 5 Body size and growth indices by social deprivation

\begin{tabular}{|c|c|c|c|}
\hline Growth index & $\begin{array}{l}\text { Most deprived quarter } \\
(\mathrm{n}=294) \text {, mean }(\mathrm{SD})\end{array}$ & $\begin{array}{l}\text { Less deprived three quarters } \\
\text { ( } n=1012 \text { ), mean (SD) }\end{array}$ & Difference $(95 \% \mathrm{Cl})$ \\
\hline \multicolumn{4}{|l|}{ Body size } \\
\hline Birth weight (g) & $3318(495)$ & $3421(447)$ & 103 (43 to 162 ) \\
\hline Birth weight ( $z$ score) & $-0.19(1.01)$ & $0.01(0.92)$ & $0.20(0.08$ to 0.32$)$ \\
\hline 6 week weight ( $z$ score) & $0.00(1.24)$ & $0.24(1.14)$ & $0.24(0.08$ to 0.39$)$ \\
\hline 18 month weight ( $z$ score) & $0.29(1.42)$ & $0.39(1.33)$ & $0.09(-0.08$ to 0.27$)$ \\
\hline Weight at age 7 ( $z$ score) & $0.24(1.65)$ & $0.28(1.52)$ & $-0.12(-0.25$ to 0.01$)$ \\
\hline Height at age 7 ( $z$ score) & $-0.14(1.02)$ & $0.11(0.99)$ & $0.24(0.11$ to 0.37$)$ \\
\hline BMl at age 7 ( $z$ score) & $0.13(1.00)$ & $-0.00(0.98)$ & $-0.13(-0.26$ to -0.00$)$ \\
\hline \multicolumn{4}{|c|}{ Change in body size (that is, weight $z$ score) } \\
\hline Birth to 6 weeks ( $z$ score) & $0.19(1.15)$ & $0.23(1.00)$ & $0.04(-0.09$ to 0.17$)$ \\
\hline 6 weeks to 18 months ( $\mathrm{z}$ score) & $0.29(1.35)$ & $0.15(1.29)$ & $-0.15(-0.31$ to 0.02$)$ \\
\hline Birth to 18 months ( $z$ score) & $0.49(1.46)$ & $0.38(1.36)$ & $-0.11(-0.29$ to 0.07$)$ \\
\hline
\end{tabular}


to implicate current environment. Better models of growth that compare the individual's growth to his or her own maximal potential (assuming such a potential exists), say by incorporating parental heights, may be more insightful.

\section{Social deprivation and child obesity}

Social deprivation was found to be an important determinant of childhood obesity. Deprived children put on most weight after 6 weeks of life; they were also less likely to be breast fed ( $31 \% \vee 54 \% ; \mathrm{p}<0.001$ ), although breast feeding status itself was not an independent predictor of BMI in this cohort. These findings are consistent with the results of a systematic review that have found a consistent relationship between adult obesity and social deprivation in childhood but not with breast feeding ${ }^{29}$; however, a more comprehensive quantitative review indicated that there is a small protective influence of breast feeding. ${ }^{30}$ Adult obesity is less consistently related to social deprivation in adulthood than in childhood. ${ }^{29}$ The relative deprivation of Plymouth, along with a strong social gradient, may explain why the link was observed in this study.${ }^{14}$ Circumstances in early life can influence later obesity risk through persistent effects of nutrition in infancy and childhood, psychological factors such as emotional deprivation in childhood, or habits relating to diet and physical activity acquired in childhood and persisting in later life. ${ }^{29} 31$ Genetic factors may also be related both to social circumstances and obesity. However, the crossover in social gradient in obesity (that is, from being more common in individuals from a higher social class previously to now becoming more common in those from a lower social class) that has occurred over a relatively short period of time does not support an important role for genetic factors in explaining the association between parental social deprivation and childhood obesity. The progressive accumulation of social deprivation related obesity risk during infancy and childhood provides additional support for the origins of obesity occurring during diffuse rather than critical window periods.

\section{Public health implications}

Evidence is accumulating on the importance and mechanisms by which growth and nutrition in early life may influence long term risks of obesity, diabetes, and cardiovascular diseases. ${ }^{25}{ }^{32}$ Better understanding of the timing of the origin of these diseases may allow us to focus interventions to periods when they could be expected to have most beneficial effect. Our data suggest that the entire perinatal period and beyond in early childhood may be important; however, our study was limited to children and it is possible that critical period effects may emerge with age. Social deprivation is an important determinant of child obesity. We did not have the data to explore the underlying mechanisms through which social deprivation may influence growth, better understanding of which may help in controlling the emerging epidemic of child obesity. The long term health implications of early growth and nutrition may also differ in important ways between high and low income countries.

In conclusion, this study suggests that obesity risk is gradually accrued over perinatal and postnatal periods rather than during a narrow critical window. Social circumstances in early life may predict which children are likely to put on weight faster in early childhood and become obese in later life.

\section{ACKNOWLEDGEMENTS}

We are grateful to Professor Tim Cole, Institute of Child Health, London for his comments on an earlier draft of this paper.

\section{CONTRIBUTORS}

JHB was one of the investigators for the growth surveillance study. SK analysed the data and wrote the first draft of the paper. All authors contributed to the final manuscript. SK is the guarantor.

\section{What is already known on this topic}

- Prenatal, early postnatal, and late postnatal life have been variously identified as critical periods for the development of obesity

\section{What this study adds}

- Obesity risk is gradually accrued over the perinatal and postnatal periods, instead of there being a critical window

- Social circumstances in early life may predict children likely to put on weight faster in early childhood and become obese in later life

\section{Authors' affiliations}

S Kinra, G Davey Smith, Department of Social Medicine, University of Bristol, Bristol, UK

J H Baumer, Department of Child Health, Derriford Hospital, Plymouth, UK

Competing interests: none declared

Ethics approval: ethical approval was not required at the time of the study

\section{REFERENCES}

1 Dietz WH. Critical periods in childhood for the development of obesity. Am J Clin Nutr 1994;59:955-9.

2 Oken E, Gillman MW. Fetal origins of obesity. Obes Res 2003;11:496-506.

3 Whitaker RC, Dietz WH. Role of the prenatal environment in the development of obesity. J Pediatr 1998;132:768-76.

4 Rogers I, EURO-BLCS Study Group. The influence of birth weight and intrauterine environment on adiposity and fat distribution in later life. Int J Obes Relat Metab Disord 2003;27:755-77.

5 Ong KK, Ahmed ML, Emmett PM, et al. Association between postnatal catchup growth and obesity in childhood: prospective cohort study. BMJ 2000;320:967-71.

6 Stettler N, Bovet $P$, Shamlaye $H$, et al. Prevalence and risk factors for overweight and obesity in children from Seychelles, a country in rapid transition: the importance of early growth. Int J Obes Relat Metab Disord 2002;26:214-19.

7 Morley R, Lucas A. Randomized diet in the neonatal period and growth performance until 7.5-8 y of age in preterm children. Am J Clin Nutr 2000;71:822-8.

8 Singhal A, Lucas A. Early origins of cardiovascular disease: is there a unifying hypothesis? Lancet 2004;363:1642-5.

9 Tanaka T, Matsuzaki A, Kuromaru R, et al. Association between birthweight and body mass index at 3 years of age. Pediatr Int 2001;43:641-6.

10 Kinra S, Nelder RP, Lewendon GJ. Deprivation and childhood obesity: a cross sectional study of 20,973 children in Plymouth, United Kingdom. J Epidemiol Community Health 2000;54:456-60.

11 Cole TJ, Freeman JV, Preece MA. British 1990 growth reference centiles for weight, height, body mass index and head circumference fitted by maximum penalized likelihood. Stat Med 1998;17:407-29.

12 Gordon D, Forrest R. People and places 2: social and economic distinctions in England. Bristol: School for Advanced Urban Studies and Bristol Statistical Monitoring Unit, 1995.

13 Lucas A, Fewtrell MS, Cole TJ. Fetal origins of adult disease - the hypothesis revisited. BMJ 1999;319:245-9.

14 Mackenzie IF, Nelder R, Maconachie M, et al. My ward is more deprived than yours. J Public Health Med 1998;20:186-90.

15 Bundred P, Kitchiner D, Buchan I. Prevalence of overweight and obese children between 1989 and 1998: population based series of cross sectional studies. BMJ 2001;322:326.

16 Pietilainen KH, Kaprio J, Rasanen M, et al. Tracking of body size from birth to late adolescence: contributions of birth length, birth weight, duration of gestation, parents' body size, and twinship. Am J Epidemiol 2001;154:21-9.

17 Mellbin T, Vuille JC. Relationship of weight gain in infancy to subcutaneous fat and relative weight at $101 / 2$ years of age. Br J Prev Soc Med 1976;30:239-43

18 Stettler N, Zemel BS, Kumanyika S, et al. Infant weight gain and childhood overweight status in a multicenter, cohort study. Pediatrics 2002;109:194-9.

19 Stettler N, Kumanyika SK, Katz SH, et al. Rapid weight gain during infancy and obesity in young adulthood in a cohort of African Americans. Am J Clin Nutr 2003;77:1374-8. 
20 Skinner JD, Bounds W, Carruth BR, et al. Predictors of children's body mass index: a longitudinal study of diet and growth in children aged $2-8 \mathrm{y}$. Int J Obes Relat Metab Disord 2004;28:476-82.

21 Eid EE. Follow-up study of physical growth of children who had excessive weight gain in first six months of life. BMJ 1970;2:74-6.

22 Stetler N, Stallings VA, Troxel AB, et al. Weight gain in the first week of life and overweight in adulthood. A cohort study of European American subjects fed infant formula. Circulation 2005;111:1897-1903.

23 Monteiro POA, Victoria CG. Rapid growth in infancy and childhood and obesity in later life - a systematic review. Obes Rev 2005;6:143-54.

24 Morton V, Torgerson DJ. Effect of regression to the mean on decision making in health care. BMJ 2003:326:1083-4.

25 Singhal A, Fewtrell $M$, Cole TJ, et al. Low nutrient intake and early growth for later insulin resistance in adolescents born preterm. Lancet 2003;361:1089-97.
26 Singhal A, Wells J, Cole TJ, et al. Programming of lean body mass: a link between birth weight, obesity, and cardiovascular disease? Am J Clin Nutr 2003;77:726-30.

27 Karlberg J, Albertsson Wikland K. Growth in full-term small-for-gestationalage infants: from birth to final height. Pediatr Res 1995:38:733-9.

28 Boersma B, Wit JM. Catch-up growth. Endocr Rev 1997; 18:646-61

29 Parsons TJ, Power C, Logan S, et al. Childhood predictors of adult obesity: a systematic review. Int J Obes 1999;23:S1-107.

30 Owen CG, Martin R, Whincup PH, et al. The effect of infant feeding on the risk of obesity across the lifecourse: a quantitative review of published evidence. Pediatrics 2005; 115:1367-77.

31 Power C, Parsons T. Nutritional and other influences in childhood as predictors of adult obesity. Proc Nutr Soc 2000;59:267-72.

32 Bhargava SK, Sachdev HS, Fall CH, et al. Relation of serial changes in childhood body-mass index to impaired glucose tolerance in young adulthood. N Engl J Med 2004;350:865-75

\section{IMAGES IN PAEDIATRICS}

\section{Klippel-Trenaunay syndrome}

A 28 year old woman with a history of Klippel-Trenaunay syndrome (KTS) presented to the hospital for an elective amputation of the right lower extremity. KTS is a congenital vascular malformative syndrome involving capillary, lymphatic, and venous structures and is associated with limb (usually asymmetric lower extremity) involvement. The patient had a history of extensive lymphatic and vascular malformations involving both lower extremities since birth, with asymmetric hypertrophy of the right leg, thigh, and buttock, and an associated flexion contracture of the right knee. Since infancy, she had undergone multiple surgical excisions of skin and soft tissues of both legs and perineum, as well as splenectomy, urinary bladder reconstruction, and partial colectomy to ameliorate visceral manifestations of the syndrome. The non-functional right lower extremity was amputated, as it was a source of intractable and severe pain. External examination showed diffuse hypertrophy, with fluctuant, discoloured cutaneous blebs, nearly confluently distributed over the knee and thigh (fig 1A). Cross-section (fig 1B) showed a diffuse proliferation of ectatic vascular spaces throughout the soft tissues, some of which were cavernous and filled with blood and phleboliths.
Microscopic examination (fig $\mathrm{IC}$ ) revealed innumerable lymphatic and venous malformations within the soft tissues. Four years later, the patient continues to suffer from chronic pain with visceral abdominal and pelvic involvement. As this case shows, clinical management of this congenital vascular malformation continues to be a difficult challenge, which does not necessarily become easier as patients grow older.

B R Pawel

Department of Pathology and Laboratory Medicine, The Children's Hospital of Philadelphia and The University of Pennsylvania School of Medicine, Philadelphia, Pennsylvania, USA

K Spencer

Department of Pathology and Laboratory Medicine, The Children's Hospital of Philadelphic

J Dormans

Division of Orthopaedic Surgery, The Children's Hospital of Philadelphia and The University of Pennsylvania School of Medicine

Correspondence to: Dr B R Pawel, Department of Pathology and Laboratory Medicine, The Children's Hospital of Philadelphia and The University of Pennsylvania School of Medicine, 324 S. 34th St, Philadelphia PA 19104, USA; pawelb@email.chop.edu Competing interests: none declared


Figure 1 (A) Amputation specimen, right lower extremity. (B) Cross-section of leg. (C) Microscopic appearance of dilated vascular spaces (trichrome elastic stain, $40 \times 1$. 